\title{
Atomization and Changes in Chemical Composition by Laser Ablation in Liquid prior to Determination of Trace Elements in Gallium Nitride
}

\author{
Koki Hirosawa and Naoki Furuta ${ }^{\dagger}$ \\ Faculty of Science and Engineering, Department of Applied Chemistry, Chuo University, 1-13-27 Kasuga, Bunkyo, \\ Tokyo 112-8551, Japan
}

\begin{abstract}
Trace elements contained in single-crystal gallium nitride $(\mathrm{GaN})$, which is a refractory material, were determined by inductively coupled plasma mass spectrometry with laser ablation in liquid (LAL) sampling. Particle size analysis by dynamic light scattering confirmed that LAL atomized the single-crystal GaN, and scanning electron microscopy/energydispersive X-ray spectrometry revealed that LAL sampling converted the GaN to gallium oxide particles. The atomization and changes in the chemical composition allowed for easy digestion of the sampled particles with nitric acid and a hot plate instead of with hydrochloric or sulfuric acid, a microwave digestion system, and a high-pressure vessel. Trace element analysis revealed the presence of trace $\mathrm{Mg}, \mathrm{Ge}, \mathrm{Y}$, and $\mathrm{Cd}$ in single-crystal $\mathrm{GaN}$, and the detection limits for these elements were $0.1-2 \mathrm{mg} \mathrm{kg}^{-1}$. The uncertainty derived from the small amount of sample used, which is a disadvantage of LAL sampling, was reduced by calculating the amount of sample ablated by measuring the concentration of the major element, Ga. We expect that the trace-element profiles of other refractory materials will be able to be determined by using this analytical approach.
\end{abstract}

Keywords Gallium nitride, laser ablation in liquid, ICPMS, uncertainty calculation

(Received December 7, 2018; Accepted January 9, 2019; Advance Publication Released Online by J-STAGE January 18, 2019)

\section{Introduction}

Gallium nitride $(\mathrm{GaN})$ is a refractory material used in blue lightemitting diodes, lasers, and semiconductor detectors. ${ }^{1-3} \mathrm{GaN}$ is also a potentially useful semiconductor for power electronics because of its wide band gap, high dielectric breakdown field strength, and high thermal conductivity; 4,5 however, these properties can be affected by the presence of trace elements, ${ }^{1}$ such as $\mathrm{Mg}, \mathrm{Ge}$, and $\mathrm{Cd}$. GaN reacts poorly with acids due to its chemical stability, which makes the determination of its trace element profile difficult. ${ }^{6,7}$ To address this issue, depth profiles of elements in $\mathrm{GaN}$ have been obtained by the direct analysis of solid samples by laser ablation inductively coupled plasma mass spectrometry (ICPMS) and secondary ion mass spectrometry; ${ }^{8-10}$ however, these analytical methods cannot be used for quantitative analysis because certified reference materials with a matrix similar to that of $\mathrm{GaN}$ are required. Thus, a highly sensitive analytical method for quantifying trace elements in $\mathrm{GaN}$ is needed.

Recently, the use of laser ablation in liquid (LAL) sampling for the determination of trace elements in silicon carbide, which, like $\mathrm{GaN}$, is also a refractory material, has been reported. ${ }^{11,12}$ In LAL sampling, a laser is used to atomize part of a solid material and produce a suspension of nanoparticles that can then be analyzed. Machida et al. reported that sintered and single-

† To whom correspondence should be addressed.

E-mail: nfuruta@chem.chuo-u.ac.jp crystal silicon carbide were easily sampled by LAL, and that nanoparticles with a different chemical composition to that of the original sample were obtained; however, high-pressure acid digestion with sulfuric acid was still needed to digest the nanoparticles before analysis, which took a long time and was subject to serious spectral interferences. ${ }^{11}$ Fujiwara et al. evaluated the uncertainties associated with LAL sampling, and concluded that there was room to improve the uncertainty derived from a small amount of sample by weighing with a microbalance, which was larger than other uncertainties. ${ }^{12}$

In the present study, we examined the differences between single-crystal GaN before and after LAL sampling, and devised an analytical method to easily and precisely quantify the trace elements in a sample of GaN. In LAL sampling, when a nanosecond laser is used, two types of particles are produced: ${ }^{13}$ large particles that are generated by the shockwave produced by the laser, and small particles that are produced by the melting and congelation of the sample due to interactions between the sample and the laser plume. We hypothesized that the laserinduced plasma produced during LAL sampling would alter the chemical composition of the $\mathrm{GaN}$ and provide particles that could be easily digested without the need for high pressures and sulfuric acid. To examine this hypothesis, we subjected GaN to LAL sampling and then measured the size distribution and chemical composition of the obtained particles by dynamic light scattering (DLS) and scanning electron microscopy/energydispersive X-ray spectrometry (SEM-EDX), respectively. We then digested the sampled particles and determined their trace element and Ga contents by ICPMS. The precision of the 
Glass SRM

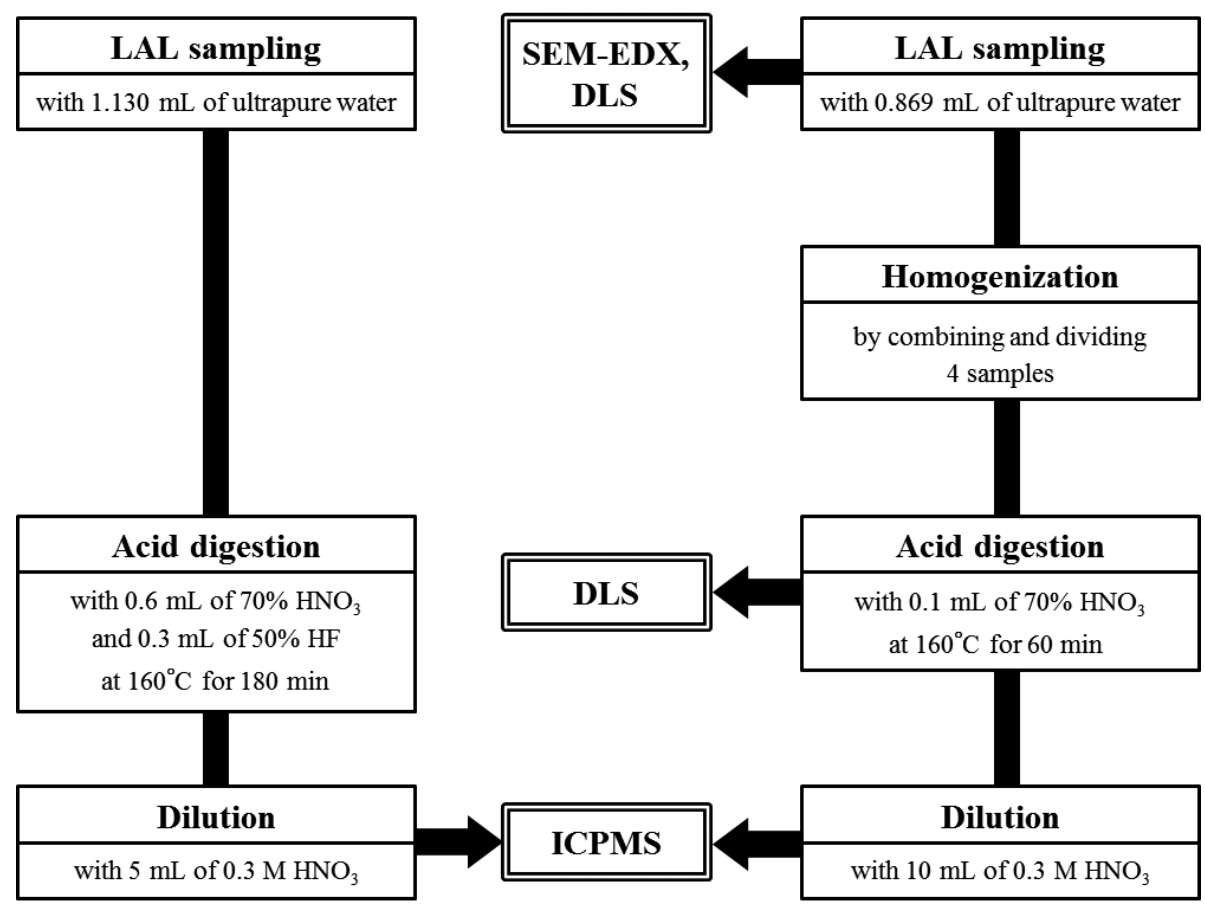

Fig. 1 Procedures for sample preparation for the analysis of a glass SRM and single-crystal gallium nitride by SEM-EDX, DLS, and ICPMS.

analytical results was improved by measuring the concentration of $\mathrm{Ga}$, the major element in $\mathrm{GaN}$, to calculate the amount of sample ablated because it eliminated the uncertainty associated with weighing.

\section{Experimental}

\section{Sample and reagents}

Single-crystal GaN was purchased from a semiconductor manufacturer. A glass standard reference material (SRM) (NIST 610, National Institute of Standards and Technology, Gaithersburg, MD) was used to validate the LAL sampling and a correction for the amount of single-crystal GaN by measuring the concentration of the major element $(\mathrm{Ga})$. Ultrapure water ( $>18.2 \mathrm{M} \Omega \mathrm{cm}$, Milli-Q, Merck Millipore, Molsheim, France), nitric acid $\left(\mathrm{HNO}_{3}\right)(\mathrm{EL}, 70 \%$, Kanto Chemical Co., Tokyo, Japan), and hydrofluoric acid (HF) (50\%, Daikin Industries, Osaka, Japan) were used for sample preparation.

Single-element solutions of $\mathrm{Mg}, \mathrm{Fe}, \mathrm{Ni}, \mathrm{Ge}, \mathrm{Rb}, \mathrm{Sr}, \mathrm{Y}$, and $\mathrm{Cd}$ (Kanto Chemical Co., Tokyo, Japan) and a multi-element solution of $\mathrm{Cr}, \mathrm{Mn}, \mathrm{Cu}, \mathrm{As}, \mathrm{Se}, \mathrm{Ag}, \mathrm{Cd}, \mathrm{Sb}, \mathrm{Ba}, \mathrm{Tl}, \mathrm{Pb}, \mathrm{Th}$, and U (XSTC-384, SPEX CertiPrep, Metuchen, NJ) were used as elemental standards for the determination of trace elements in the glass SRM and single-crystal GaN. Single-element solutions of $\mathrm{Ca}$ and $\mathrm{Ga}$ (Kanto Chemical Co.) were used to determine the amount of sample ablated. A single-element solution of $\mathrm{Rh}$ (Kanto Chemical Co.) was used for correcting sensitivity of the ICPMS instrument. These standard solutions were diluted with $0.3 \mathrm{M} \mathrm{HNO}_{3}$ to prepare calibration solutions.

\section{Instrumentation}

A laser ablation system (UP213, Elemental Scientific Laser,
Bozeman, MT) was used for LAL sampling. An ICPMS instrument equipped with a quadrupole (7500ce, Agilent Technologies, Tokyo, Japan) was used to determined the elemental concentrations in a digested $\mathrm{GaN}$ solution. A semimicrobalance (AE240, Mettler Toledo, Zürich, Switzerland) was used to weigh the sample solutions. A particle size analyzer (ELSZ-2000, Otsuka Electronics, Osaka, Japan) equipped with a DLS system was used to measure the size distribution of LALsampled GaN particles. An SEM-EDX instrument (S-5500, Hitachi High-Technology Co., Tokyo, Japan) was used to investigate the size, shape, and chemical composition of LALsampled GaN particles.

\section{LAL sampling}

The analytical procedures used in the present study are summarized in Fig. 1. A sample of the glass SRM (1.3 g) or a piece of single-crystal GaN (340 mg) was placed in an open-top chamber made of tetrafluoroethylene-perfluoroalkyl vinyl copolymer (PFA), and $1.130 \mathrm{~mL}$ (for the glass SRM) or $0.869 \mathrm{~mL}$ (for the single-crystal $\mathrm{GaN}$ ) of ultrapure water was added to the chamber. The outer diameter, inner diameter and height of the chamber were 27,18 and $13 \mathrm{~mm}$, respectively. The depth between the surface of the solid sample and the surface of the water was adjusted to $3 \mathrm{~mm}$, which was adjusted by calculating the volume. Table 1 gives the LAL operating conditions. A $2 \times 2 \mathrm{~mm}^{2}$ area on the surface of the sample was ablated with the laser ablation system. The repetition rate and the spot size were optimized so as to increase the amount of sample ablated. The LAL sampling for a long time caused a reduction of the laser energy. Thus, the sampling time was optimized for $70 \mathrm{~min}$, which did not reduce the laser energy within a day. As a result of the LAL, approximately $80 \mu \mathrm{g}$ of the glass SRM or approximately $20 \mu \mathrm{g}$ of the single-crystal 
Table 1 LAL operating conditions

\begin{tabular}{ll}
\hline \multicolumn{2}{c}{ Laser ablation system (UP213) } \\
\hline Laser type & Nd:YAG \\
Wavelength & $213 \mathrm{~nm}$ \\
Laser energy at sample surface & $0.40 \mathrm{~mJ}$ \\
Fluence at sample surface & $5.1 \mathrm{~J} \mathrm{~cm}$ \\
Repetition rate & $20 \mathrm{~Hz}$ \\
Spot size & $100 \mu \mathrm{m}$ \\
Scanning speed & $10 \mu \mathrm{m} \mathrm{s}^{-1}$ \\
Ablation area & $4 \mathrm{~mm}^{2}$ \\
Sampling time & $70 \mathrm{~min}^{2}$ \\
\hline
\end{tabular}

Table 2 Ununiformity of trace elements on the surface of single-crystal gallium nitride, as determined by LAL-ICPMS

\begin{tabular}{cccc}
\hline & \multicolumn{3}{c}{ Concentration $/ \mathrm{mg} \mathrm{kg}^{-1}$} \\
\cline { 2 - 4 } & Sample 1 & Sample 2 & Sample 3 \\
\hline $\mathrm{Mg}$ & 678 & 111 & 99.7 \\
$\mathrm{Y}$ & 6.87 & $<0.1^{\mathrm{a}}$ & 2.34 \\
\hline
\end{tabular}

a. Not detected.

GaN per sample was collected in the water, and the suspension was transferred to a 33-mL PFA vial. Four suspensions were obtained by LAL for each sample. A preliminary experiment revealed that trace elements were not distributed uniformly on the surface of the single-crystal GaN (Table 2); therefore, the LAL-sampled $\mathrm{GaN}$ suspensions obtained from different areas were combined, and the suspension was divided into four samples to make homogeneous samples. The size, shape, and chemical composition, and the size distribution, of the obtained particles were determined by SEM-EDX and DLS, respectively.

\section{Acid digestion and ICPMS measurement}

To digest the obtained particles, $0.6 \mathrm{~mL}$ of $70 \% \mathrm{HNO}_{3}$ and $0.3 \mathrm{~mL}$ of $50 \% \mathrm{HF}$ (for the glass SRM) or $0.1 \mathrm{~mL}$ of $70 \%$ $\mathrm{HNO}_{3}$ (for single-crystal GaN) were added to the sample suspension in the PFA vial. The vial was then heated on a hotplate at $160^{\circ} \mathrm{C}$ for $180 \mathrm{~min}$ (for the glass SRM) or $60 \mathrm{~min}$ (for single-crystal $\mathrm{GaN}$ ) to decompose the samples; the resulting solution was diluted to 5 or $10 \mathrm{~mL}$ with $0.3 \mathrm{M} \mathrm{HNO}_{3}$, respectively. Further, ICPMS measurements were performed under the operating conditions given in Table 3.

In the ICPMS analysis of the glass SRM, $\mathrm{H}_{2}$ or He was used as the collision/reaction cell (CRC) gas to solve spectral interferences derived from $\mathrm{Ar}$ and the matrix, respectively. To increase the sensitivity of the method, a CRC gas was not used for the single-crystal GaN. The major elements, which were $\mathrm{Si}$, $\mathrm{Na}, \mathrm{Ca}$ and $\mathrm{Al}$ for the glass SRM and Ga for single-crystal GaN, were added to the calibration solutions so that the matrix of the calibration solutions matched that of the sample solutions.

\section{Determination of uncertainty}

The concentration of a trace element $(X)$ or a major element $(\mathrm{Y})$ in a solid sample $(\mathrm{Z})$ is expressed by the following equations:

$$
C_{\text {solid }}(\mathrm{X})=\frac{m_{\text {solid }}(\mathrm{X})}{m_{\text {solid }}(\mathrm{Z})}
$$

Table 3 ICPMS operating conditions

\begin{tabular}{|c|c|c|c|}
\hline \multicolumn{4}{|c|}{ ICPMS (Agilent 7500ce) } \\
\hline Sample & \multicolumn{2}{|c|}{ Glass SRM } & $\begin{array}{c}\text { Single-crystal } \\
\text { GaN }\end{array}$ \\
\hline CRC gas & $\mathrm{H}_{2}$ & $\mathrm{He}$ & None \\
\hline Plasma gas flow & $15.00 \mathrm{~L} \mathrm{~min}^{-1}$ & $15.00 \mathrm{~L} \mathrm{~min}^{-1}$ & $15.00 \mathrm{~L} \mathrm{~min}^{-1}$ \\
\hline Auxiliary gas flow & $1.50 \mathrm{~L} \mathrm{~min}^{-1}$ & $1.50 \mathrm{~L} \mathrm{~min}^{-1}$ & $1.50 \mathrm{~L} \mathrm{~min}^{-1}$ \\
\hline Carrier gas flow & $0.88 \mathrm{~L} \mathrm{~min}^{-1}$ & $0.90 \mathrm{~L} \mathrm{~min}^{-1}$ & $0.94 \mathrm{~L} \mathrm{~min}^{-1}$ \\
\hline CRC gas flow & $4.0 \mathrm{~mL} \mathrm{~min}^{-1}$ & $2.9 \mathrm{~mL} \mathrm{~min}^{-1}$ & - \\
\hline \multicolumn{4}{|l|}{ Measured isotopes } \\
\hline Major element & \multicolumn{2}{|c|}{${ }^{40} \mathrm{Ca}$} & ${ }^{69} \mathrm{Ga}$ \\
\hline Internal standard & \multicolumn{2}{|c|}{${ }^{103} \mathrm{Rh}$} & ${ }^{103} \mathrm{Rh}$ \\
\hline Trace elements & $\begin{array}{l}{ }^{52} \mathrm{Cr},{ }^{55} \mathrm{Mn},{ }^{75} \mathrm{As}, \\
{ }^{80} \mathrm{Se},{ }^{85} \mathrm{Rb},{ }^{107} \mathrm{Ag}, \\
{ }^{111} \mathrm{Cd},{ }^{121} \mathrm{Sb}, \\
{ }^{137} \mathrm{Ba},{ }^{205} \mathrm{Tl}, \\
{ }^{206} \mathrm{~Pb},{ }^{232} \mathrm{Th},{ }^{238} \mathrm{U}\end{array}$ & $\begin{array}{l}{ }^{56} \mathrm{Fe},{ }^{60} \mathrm{Ni}, \\
{ }^{63} \mathrm{Cu},{ }^{88} \mathrm{Sr}\end{array}$ & $\begin{array}{l}{ }^{24} \mathrm{Mg},{ }^{70} \mathrm{Ge}, \\
{ }^{89} \mathrm{Y},{ }^{111} \mathrm{Cd}\end{array}$ \\
\hline
\end{tabular}

$$
C_{\text {solid }}(\mathrm{Y})=\frac{m_{\text {solid }}(\mathrm{Y})}{m_{\text {solid }}(\mathrm{Z})}
$$

where $C$ is the concentration, $m$ is the mass, and the subscript "solid" indicates a solid sample. Equation (1) can be transformed to the following equation:

$$
C_{\text {solid }}(\mathrm{X})=\frac{m_{\text {solid }}(\mathrm{X})}{m_{\text {solid }}(\mathrm{Y})} \cdot C_{\text {solid }}(\mathrm{Y})
$$

The mass ratio of trace element $\mathrm{X}$ to the major element $\mathrm{Y}$ in a solid sample is equal to the concentration ratio of those elements in a solution of digested LAL-sampled particles:

$$
\frac{m_{\text {solid }}(\mathrm{X})}{m_{\text {solid }}(\mathrm{Y})}=\frac{C_{\text {solution }}(\mathrm{X})}{C_{\text {solution }}(\mathrm{Y})}
$$

The subscript "solution" indicates a solution of digested LALsampled particles. By substituting Eq. (4) into Eq. (3), the following equation is obtained:

$$
C_{\text {solid }}(\mathrm{X})=\frac{C_{\text {solution }}(\mathrm{X})}{C_{\text {solution }}(\mathrm{Y})} \cdot C_{\text {solid }}(\mathrm{Y})
$$

The concentration ratio of trace element $\mathrm{X}$ to major element $\mathrm{Y}$ in the digested solution is calculated with a calibration curve and the following equation:

$$
\frac{I_{\text {solution }}(\mathrm{X})}{I_{\text {solution }}(\mathrm{Y})}=a \cdot \frac{C_{\text {solution }}(\mathrm{X})}{C_{\text {solution }}(\mathrm{Y})}+b
$$

where $I$ is the signal intensity measured by ICPMS; $a$ and $b$ are the slope and intercept of the calibration curve, respectively. By defining $R \equiv \frac{I(\mathrm{X})}{I(\mathrm{Y})}$, the concentration of trace element $\mathrm{X}$ in the solid sample is calculated by using the following equation:

$$
C_{\text {solid }}(\mathrm{X})=\frac{R_{\text {solution }}-b}{a} \cdot C_{\text {solid }}(\mathrm{Y})
$$

The combined uncertainty for the concentration of trace element $\mathrm{X}$ is calculated as the sum of four relative standard uncertainties (RSUs): ${ }^{14}$ 
(a)

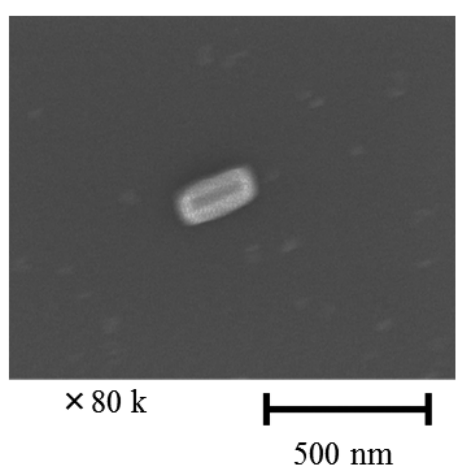

(b)

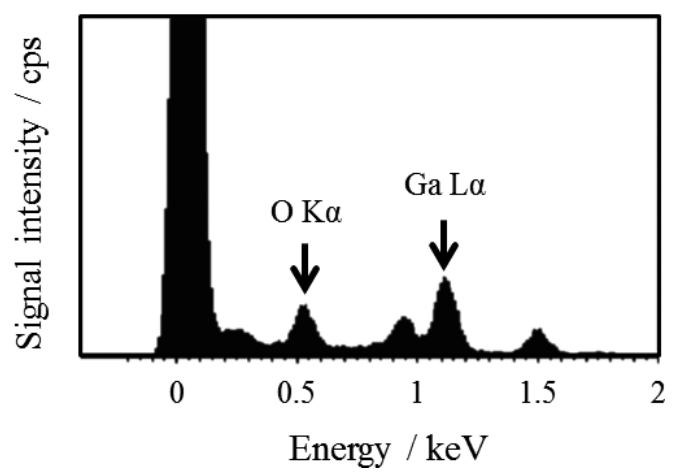

Fig. 2 SEM-EDX analysis of LAL-sampled particles. (a) Representative SEM image of a single particle. (b) EDX spectrum.

$$
\begin{gathered}
\left(\frac{u_{\mathrm{c}}}{C_{\text {solid }}(\mathrm{X})}\right)^{2}=(\text { RSU of samples })^{2}+(\text { RSU of calibration })^{2}+ \\
(\mathrm{RSU} \text { of standard })^{2}+(\text { RSU of major element })^{2}
\end{gathered}
$$

The terms on the right side of Eq. (8) correspond to the sample repeatability, the uncertainty of the calibration curve, the uncertainty of the concentration of the standard solutions, and the uncertainty of the concentration of the major element in the solid sample Z, which is used for calculating the ablated amount of sample, respectively. By defining $\alpha \equiv \frac{R_{\text {solution }}-b}{a}$, the RSUs are calculated by the following equations: ${ }^{15}$

$$
\begin{aligned}
& (\text { RSU of samples })^{2}=\left(\frac{\text { RSD of } y_{\text {solution }}}{\sqrt{n}}\right)^{2} \\
& (\text { RSU of calibration })^{2}= \\
& \frac{\frac{1}{a^{2}} u^{2}\left(R_{\text {solution }}\right)+\frac{\left(R_{\text {solution }}-b\right)^{2}}{a^{4}} u^{2}(a)+\frac{1}{a^{2}} u^{2}(b)+\frac{2\left(R_{\text {solution }}-b\right)}{a^{3}} u(a, b)}{\alpha^{2}}
\end{aligned}
$$

$(\mathrm{RSU} \text { of standard })^{2}=\left(\frac{u\left(C_{\text {standard }}(\mathrm{X})\right)}{C_{\text {standard }}(\mathrm{X})}\right)+\left(\frac{u\left(C_{\text {standard }}(\mathrm{Y})\right)}{C_{\text {standard }}(\mathrm{Y})}\right)^{2}$

where $n$ indicates the number of samples. The values of $u^{2}(a)$, $u^{2}(b)$, and $u(a, b)$ are approximated by the residual standard deviation. ${ }^{15}$

For the glass SRM, the concentration of the major element, $\mathrm{Ca}$, and associated uncertainty are as follows: ${ }^{16}$

$$
C_{\text {solid }}(\mathrm{Y})=C_{\text {solid }}(\mathrm{Ca})
$$

$(\text { RSU of major element })^{2}=(0.61 \%)^{2}$

For a solid sample of single-crystal GaN, which is highly pure, the concentration of the major element, $\mathrm{Ga}$, is equal to the ratio of the atomic and molecular weights. Hence, the concentration of the major element and the associated uncertainty are approximated as follows:

$$
C_{\text {solid }}(\mathrm{Y})=\frac{M(\mathrm{Ga})}{M(\mathrm{GaN})}
$$

$(\mathrm{RSU} \text { of major element })^{2}=$

$$
\left(\frac{u(M(\mathrm{Ga}))}{M(\mathrm{Ga})}\right)^{2}+\left(\frac{u(M(\mathrm{GaN}))}{M(\mathrm{GaN})}\right)^{2}
$$

where $M$ indicates the atomic or molecular weight. The atomic weights used in the calculations were obtained from Atomic weights of the elements $2013 .{ }^{17}$

\section{Results and Discussion}

SEM-EDX analysis of LAL-sampled particles produced from GaN

The size, shape, and chemical composition of LAL-sampled particles produced from single-crystal GaN were investigated by SEM-EDX. SEM revealed that many particles with a diameter of several hundred nanometers were produced (Fig. 2a). The small size and round shape of the particles suggested they were produced by melting and congelation due to interactions between the laser plume and the sample. EDX analysis of the particles revealed the presence of gallium and oxygen, but not nitrogen, indicating a change in the chemical composition from gallium nitride to gallium oxide (Fig. 2b). The change in the chemical composition to gallium oxide suggested that the particles would be easily decomposed with $\mathrm{HNO}_{3}$, and so the use of hydrochloric acid and sulfuric acid, which cause spectral interferences, could be avoided. ${ }^{18}$

\section{Digestion of LAL-sampled particles}

The particle size distribution of the LAL-sampled particles, and whether the particles were decomposed with $\mathrm{HNO}_{3}$, were investigated by DLS analysis. The average diameter of the particles was approximately $150 \mathrm{~nm}$, and there were no large particles $(>1 \mu \mathrm{m})$ (Fig. 3a). This result was obtained by using a low laser fluence ( $c a .5 .1 \mathrm{~J} \mathrm{~cm}^{-2}$ ), but when a high laser fluence was used, particles with larger than $1 \mu \mathrm{m}$ were observed. This finding was consistent with previous reports showing that a low laser fluence suppresses the production of large particles by the laser shockwave. ${ }^{19,20}$ The autocorrelation function of the DLS measurement showed a fluctuation in the scattering signal intensity that was related to the particle size. The two lines of "after acid digestion" and "blank" almost unchanged from 1, which indicated no particles, and the line of "before acid digestion" approached to 1 with time (Fig. 3b). The behavior of 
(a)

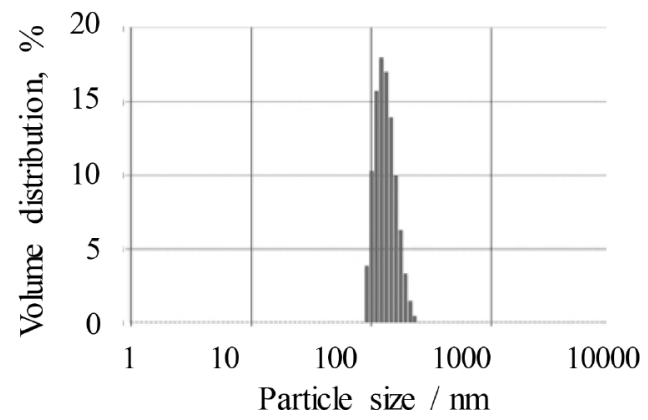

(b)

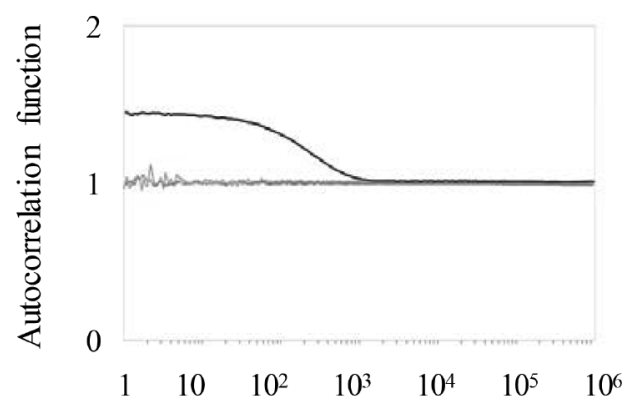

Time from the start of DLS measurement / $\mu \mathrm{s}$

Fig. 3 DLS measurement of LAL-sampled particles. (a) Particle size distribution. (b) Autocorrelation function before and after acid digestion. - - - - blank (ultrapure water).

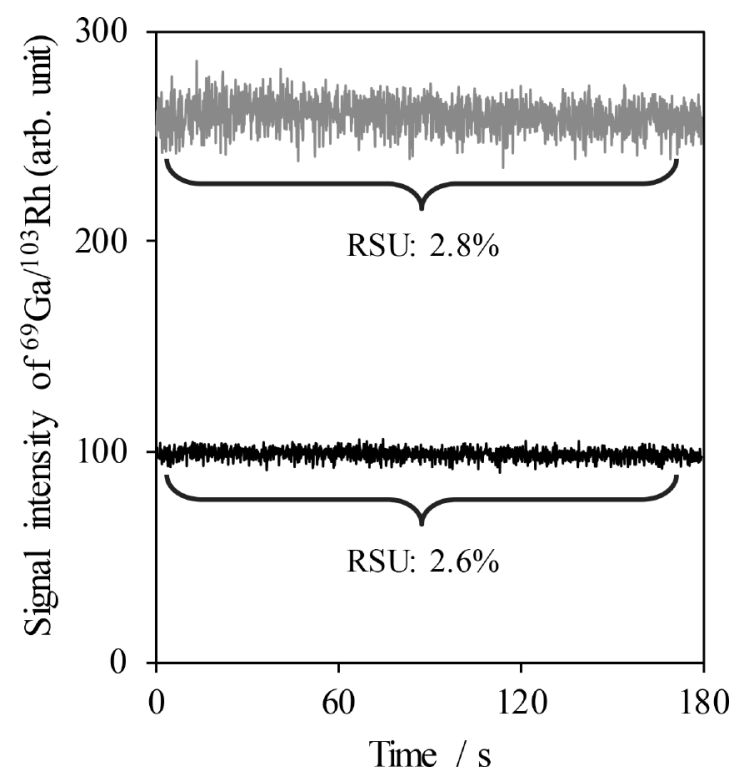

Fig. 4 Time-resolved spectra of a digested gallium nitride solution and a gallium standard solution $\left(3 \mathrm{mg} \mathrm{kg}^{-1}\right) . \stackrel{\text { Dagested gallium }}{\longrightarrow}$ nitride solution; __

the autocorrelation function for the LAL-sampled particles after acid digestion coincided with that of a blank (ultrapure water), confirming that the LAL-sampled particles were digested with $\mathrm{HNO}_{3}$ and a hot plate.

Time-resolved analysis of digested single-crystal GaN solution Large particles that were not digested, but not detected in the DLS analysis, could cause spike noise and changes in the introduction efficiency of the sample solution that affect the determination of trace elements by ICPMS; therefore, we compared the signal intensities for $\mathrm{Ga}$ in a digested $\mathrm{GaN}$ solution and in a Ga standard solution to check for spiking noise derived from any undigested particles (Fig. 4). No spiking noise was detected, and there were no differences between the RSUs for the digested GaN solution and that for the Ga standard solution. Thus, no particles remained after digestion, and a quantitative measurement by ICPMS would not be affected.
Table 4 Quantitative values of trace elements in a glass SRM, as determined by LAL-ICPMS $(n=4)$

\begin{tabular}{lcccc}
\hline & Determined/mg kg-1 & Certified/mg kg-1 & CRC gas \\
\hline $\mathrm{Cr}$ & $431 \pm 20$ & $415 \pm 29$ & $\mathrm{H}_{2}$ \\
$\mathrm{Mn}$ & $468 \pm 13$ & $457 \pm 55$ & $\mathrm{H}_{2}$ \\
$\mathrm{Fe}$ & $567 \pm 117$ & $458 \pm 9$ & $\mathrm{He}$ \\
$\mathrm{Ni}$ & $480 \pm 26$ & $458.7 \pm 4$ & $\mathrm{He}$ \\
$\mathrm{Cu}$ & $481 \pm 22$ & $444 \pm 4$ & $\mathrm{He}$ \\
$\mathrm{As}$ & $318 \pm 20$ & $340 \pm 20$ & $\mathrm{H}_{2}$ \\
$\mathrm{Se}$ & $117.3 \pm 46$ & $115.2 \pm 2.2$ & $\mathrm{H}_{2}$ \\
$\mathrm{Rb}$ & $406 \pm 36$ & $425.7 \pm 0.8$ & $\mathrm{H}_{2}$ \\
$\mathrm{Sr}$ & $508 \pm 21$ & $515.5 \pm 0.5$ & $\mathrm{He}$ \\
$\mathrm{Ag}$ & $261 \pm 35$ & $268 \pm 29$ & $\mathrm{H}_{2}$ \\
$\mathrm{Cd}$ & $257 \pm 15$ & $244 \pm 22$ & $\mathrm{H}_{2}$ \\
$\mathrm{Sb}$ & $420.9 \pm 6.8$ & $415.3 \pm 3.7$ & $\mathrm{H}_{2}$ \\
$\mathrm{Ba}$ & $429 \pm 23$ & $453 \pm 37$ & $\mathrm{H}_{2}$ \\
$\mathrm{Tl}$ & $56.1 \pm 59$ & $61.8 \pm 2.5$ & $\mathrm{H}_{2}$ \\
$\mathrm{~Pb}$ & $422.7 \pm 9.1$ & $426 \pm 1$ & $\mathrm{H}_{2}$ \\
$\mathrm{Th}$ & $457 \pm 11$ & $457.2 \pm 1.2$ & $\mathrm{H}_{2}$ \\
$\mathrm{U}$ & $467.9 \pm 88$ & $461.5 \pm 1.1$ & $\mathrm{H}_{2}$ \\
\hline
\end{tabular}

Mean \pm expanded uncertainty $(k=2)$.

\section{Validation of analytical method}

To validate the analytical method, the trace elements in the glass SRM were determined by LAL-ICPMS (Table 4). When $\mathrm{H}_{2}$ gas was used for the CRC gas, there were large differences between the determined and certified values for $\mathrm{Fe}, \mathrm{Ni}, \mathrm{Cu}$, and Sr. Therefore, He gas was used as the CRC gas to solve spectral interferences, such as ${ }^{40} \mathrm{Ca}^{16} \mathrm{O}\left({ }^{56} \mathrm{Fe}\right),{ }^{44} \mathrm{Ca}^{16} \mathrm{O}\left({ }^{60} \mathrm{Ni}\right),{ }^{40} \mathrm{Ca}^{23} \mathrm{Na}$ $\left({ }^{63} \mathrm{Cu}\right)$, and ${ }^{44} \mathrm{Ca}^{44} \mathrm{Ca}\left({ }^{88} \mathrm{Sr}\right)$, derived from the glass matrix. The quantitative values of all the elements, except that for $\mathrm{Cu}$, which was an information value, were in good agreement with the certified values within the ranges of uncertainty.

The uncertainties for the trace elements in the glass SRM are given in Table 5. The RSU of samples represents the uncertainty derived from the homogeneity and pretreatment of the sample. The RSU of calibration represents the uncertainty derived from the linearity of the calibration curve and the background. For $\mathrm{Fe}, \mathrm{Ag}$, and $\mathrm{Tl}$, the RSU of samples was much larger than other uncertainties, which was caused by some inhomogeneity of the elements in the sample. ${ }^{21}$ The RSU of the major element was decreased from 5\%, which was the uncertainty of the amount of sample ablated by weighing with a microbalance, to $0.61 \%$ 
Table 5 Uncertainties associated with the analysis of trace elements in a glass SRM by LAL-ICPMS $(n=4)$

\begin{tabular}{lcccccc}
\hline & \multicolumn{3}{c}{ Relative standard uncertainty, \% } & & \\
\cline { 2 - 5 } & Samples & Calibration & Standard & $\begin{array}{c}\text { Major } \\
\text { element }\end{array}$ & & \\
& & & & & \\
& & & & & \\
\hline $\mathrm{Cr}$ & 1.1 & 1.9 & 0.35 & 0.61 & 2.3 & 4.7 \\
$\mathrm{Mn}$ & 1.0 & 0.55 & 0.35 & 0.61 & 1.3 & 2.7 \\
$\mathrm{Fe}$ & 10.3 & 0.72 & 0.35 & 0.61 & 10 & 21 \\
$\mathrm{Ni}$ & 1.8 & 1.9 & 0.35 & 0.61 & 2.7 & 5.5 \\
$\mathrm{Cu}$ & 0.87 & 2.0 & 0.35 & 0.61 & 2.3 & 4.5 \\
$\mathrm{As}$ & 0.83 & 3.0 & 0.35 & 0.61 & 3.2 & 6.3 \\
$\mathrm{Se}$ & 1.8 & 0.29 & 0.35 & 0.61 & 2.0 & 4.0 \\
$\mathrm{Rb}$ & 2.2 & 3.8 & 0.35 & 0.61 & 4.5 & 8.9 \\
$\mathrm{Sr}$ & 0.80 & 1.8 & 0.35 & 0.61 & 2.1 & 4.2 \\
$\mathrm{Ag}$ & 6.7 & 0.14 & 0.35 & 0.61 & 6.7 & 13 \\
$\mathrm{Cd}$ & 2.9 & 0.39 & 0.35 & 0.61 & 3.0 & 6.0 \\
$\mathrm{Sb}$ & 0.29 & 0.29 & 0.35 & 0.61 & 0.81 & 1.6 \\
$\mathrm{Ba}$ & 2.5 & 0.074 & 0.35 & 0.61 & 2.6 & 5.3 \\
$\mathrm{Tl}$ & 5.2 & 0.42 & 0.35 & 0.61 & 5.3 & 11 \\
$\mathrm{~Pb}$ & 0.11 & 0.81 & 0.35 & 0.61 & 1.1 & 2.2 \\
$\mathrm{Th}$ & 0.56 & 0.74 & 0.35 & 0.61 & 1.2 & 2.3 \\
$\mathrm{U}$ & 0.50 & 0.38 & 0.35 & 0.61 & 0.94 & 1.9 \\
\hline
\end{tabular}

Table 6 Concentrations and detection limits of trace elements in single-crystal gallium nitride, as determined by LAL-ICPMS $(n=4)$

\begin{tabular}{lcc}
\hline & Concentration $/ \mathrm{mg} \mathrm{kg}^{-1}$ & Detection limit $/ \mathrm{mg} \mathrm{kg}^{-1}$ \\
\hline $\mathrm{Mg}$ & $187 \pm 14$ & 2 \\
$\mathrm{Ge}$ & $34.7 \pm 1.7$ & 0.9 \\
$\mathrm{Y}$ & $6.3 \pm 0.4$ & 0.1 \\
$\mathrm{Cd}$ & $24.1 \pm 0.9$ & 0.5 \\
\hline
\end{tabular}

Mean \pm expanded uncertainty $(k=2)$.

because the amount was calculated by measuring the concentration of the major element $(\mathrm{Ca})$, even though only a small amount of sample was used. This suggested that this analytical method could be used to determine the trace-element profile of a highly pure material such as GaN because the RSU of major element would be smaller due to calculating the concentration of the major element by the atomic or molecular weight.

Determination of trace elements in single-crystal GaN by LALICPMS

Table 6 gives the concentrations and detection limits of the trace elements $\mathrm{Mg}, \mathrm{Ge}, \mathrm{Y}$, and $\mathrm{Cd}$, which are used as dopants in $\mathrm{GaN}$ semiconductors, in single-crystal GaN. ${ }^{22-24}$ Hence, the analytical method can be used for determining the trace elements in GaN. Table 7 summarizes the uncertainties associated with the analysis of these four trace elements. The RSU of samples was $1.0-3.6 \%$. The RSU of the major element was much lower than that of the other uncertainties, indicating that the uncertainty associated with using only a small amount of the sample could be reduced by calculating the amount of sample ablated by measuring the concentration of the major element $(\mathrm{Ga})$. Thus, a precise determination of the trace-element profile of single-crystal GaN was achieved by using this analytical method.

There are two improvements that could be made to further reduce the RSU of calibration and the elemental detection
Table 7 Uncertainties associated with the analysis of trace elements in single-crystal gallium nitride by LAL-ICPMS $(n=4)$

\begin{tabular}{|c|c|c|c|c|c|c|}
\hline & \multicolumn{4}{|c|}{ Relative standard uncertainty, $\%$} & \multirow[b]{2}{*}{$u_{\mathrm{c}}, \%$} & \multirow[b]{2}{*}{$U, \%$} \\
\hline & Samples & Calibration & Standard & $\begin{array}{c}\text { Major } \\
\text { element }\end{array}$ & & \\
\hline $\mathrm{Mg}$ & 3.6 & 0.35 & 0.35 & 0.0020 & 3.6 & 7.3 \\
\hline $\mathrm{Ge}$ & 1.7 & 1.8 & 0.35 & 0.0020 & 2.5 & 5.0 \\
\hline Y & 2.6 & 1.0 & 0.35 & 0.0020 & 2.8 & 5.6 \\
\hline $\mathrm{Cd}$ & 1.0 & 1.6 & 0.35 & 0.0020 & 1.9 & 3.8 \\
\hline
\end{tabular}

limits. The RSUs of the calibration for Ge, Y, and Cd were equal to or greater than $1 \%$ because the concentrations of those elements in the sample solution were low ( $\left.c a .3-20 \mathrm{ng} \mathrm{kg}^{-1}\right)$. Therefore, the RSU of the calibration could be improved by using sector field-ICPMS, which is more sensitive and has a lower background than quadrupole-ICPMS. In addition, the detection limits of $\mathrm{Mg}, \mathrm{Ge}, \mathrm{Y}$, and $\mathrm{Cd}$ were high because of the high dilution factor $(\mathrm{ca} . \times 500000)$ and the small amount of sample used. Therefore, to improve the detection limits, the amount of sample ablated could be increased by using a highpower femtosecond laser and extending the ablation time, and a more sensitive analytical method such as sector field-ICPMS could be used.

\section{Conclusions}

Here, we used SEM-EDX and DLS to investigate the atomization and changes in the chemical composition of single-crystal GaN by LAL. The average diameter of LAL-sampled particles was approximately $150 \mathrm{~nm}$, and the particles consisted of gallium oxide, which allowed the GaN to be digested with $\mathrm{HNO}_{3}$ and a hot plate. The concentrations of trace elements $(\mathrm{Mg}, \mathrm{Ge}, \mathrm{Y}$, and $\mathrm{Cd}$ ) in the single-crystal GaN were determined by LAL-ICPMS, and the analytical method was validated by measuring the trace elements in a glass SRM. Precise determinations of trace elements in single-crystal GaN were achieved by calculating the amount of sample ablated by measuring the concentration of $\mathrm{Ga}$, which was the major element in $\mathrm{GaN}$. We expect that the trace element profiles of other refractory materials (e.g. barium titanate) can be determined by using this analytical approach.

\section{Acknowledgements}

This research was supported by the Ministry of Education, Culture, Sports, Science and Technology, Japan, through a Grant-in-Aid for Scientific Research (C) (No. 17K05909).

\section{References}

1. R. Rounds, B. Sarkar, T. Sochacki, M. Bockowski, M. Imanishi, Y. Mori, R. Kirste, R. Collazo, and Z. Sitar, J. Appl. Phys., 2018, 124, 105106.

2. S. Kumar, B. A. Reshi, and R. Varma, Results Phys., 2018, 11, 461.

3. S. P. DenBaars, D. Feezell, K. Kelchner, S. Pimputkar, C. C. Pan, C. C. Yen, S. Tanaka, Y. Zhao, N. Pfaff, R. Farrell, M. Iza, S. Keller, U. Mishra, J. S. Speck, and S. Nakamura, Acta Mater., 2013, 61, 945. 
4. J. Millán, P. Godignon, and A. Pérez-Tomás, Automatika, 2012, 53(2), 107.

5. A. S. Abdelrahman, Z. Erdem, Y. Attia, and M. Youssef, Can. J. Elect. Comput. Eng., 2018, 41(1), 45.

6. K. C. Wang, G. D. Yuan, R. W. Wu, H. X. Lu, Z. Q. Liu, T. B. Wei, J. X. Wang, J. M. Li, and W. J. Zhang, J. Cryst. Growth, 2016, 440, 96.

7. C. B. Vartuli, S. J. Pearton, C. R. Abernathy, J. D. MacKenzie, F. Ren, J. C. Zolper, and R. J. Shul, Solid State Electron., 1997, 41(12), 1947.

8. X. Wei, L. Zhao, J. Wang, Y. Zeng, and J. Li, Surf. Interface Anal., 2014, 46, 299.

9. S. Sintonen, S. Wahl, S. Richter, S. Meyer, S. Suihkonen, T. Schulz, K. Irmscher, A. N. Danilewsky, T. O. Tuomi, R. Stankiewicz, and M. Albrecht, J. Cryst. Growth, 2016, 456, 51.

10. N. Karar, R. Opila, T. Beebe, O. Toader, and F. Naab, ECS J. Solid State Sci. Technol., 2012, 1(4), 164.

11. R. Machida, R. Nishioka, M. Fujiwara, and N. Furuta, Anal. Sci., 2017, 33, 537.

12. M. Fujiwara, K. Hirosawa, N. Nonose, S. Nishida, and N. Furuta, Accred. Qual. Assur., accepted.

13. R. Machida, T. Nakazawa, and N. Furuta, Anal. Sci., 2015, 31, 345.

14. JCGM-100:2008, "Evaluation of Data-Guide to the
Expression of Uncertainty in Measurement".

15. D. B. Hibbert, Analyst, 2006, 131, 1273.

16. K. P. Jochum, U. Weis, B. Stoll, D. Kuzmin, Q. Yang, I. Raczek, D. E. Jacob, A. Stracke, K. Birbaum, D. A. Frick, D. Günther, and J. Enzweiler, Geostand. Geoanal. Res., 2011, 35(4), 397.

17. J. Meija, T. B. Coplen, M. Berglund, W. A. Brand, P. D. Bièvre, M. Gröning, N. E. Holden, J. Irrgeher, R. D. Loss, T. Walczyk, and T. Prohaska, Pure Appl. Chem., 2016, 88(3), 265.

18. A. Mekki-Berrada, D. Grondin, S. Bennici, and A. Auroux, Phys. Chem. Chem. Phys., 2012, 14, 4155.

19. S. H. Jeong, O. V. Borisov, J. H. Yoo, X. L. Mao, and R. E. Russo, Anal. Chem., 1999, 71, 5123.

20. I. Horn and D. Günther, Appl. Surf. Sci., 2003, 207, 144.

21. S. M. Eggins and J. M. G. Shelley, Geostand. Geoanal. Res., 2002, 26(3), 269.

22. R. J. Molnar, R. Singh and T. D. Moustakas, Appl. Phys. Lett., 1994, 64(17), 2264.

23. S. Nakamura, T. Mukai, and N. Iwasa, U. S. Patent, 1994, 5578839 .

24. P. Hofmann, M. Krupinski, F. Habel, G. Leibiger, B. Weinert, S. Eichler, and T. Mikolajick, J. Cryst. Growth, 2016, $450,61$. 